\title{
Distribution of Nutrients in the Soils of a Unique Tropical Agroecosystem
}

\author{
Thafna K.K., Navya C., Binish M.B., Gopikrishna V.G., *Mahesh Mohan \\ School of Environmental Sciences, Mahatma Gandhi University, Kottayam \\ Email: mahises@gmail.com
}

\begin{abstract}
Kuttanad agroecosystem, once the rice bowl of Kerala, is facing a serious threat from human activities. The present study assessed the nutrient status of Kuttanad paddy soils and the spatial distribution of Nutrients using GIS technique. 117 soil samples were collected from the six agroecological zones of Kuttanad. Out of the 117, 92 were from paddy fields and 25 were from canals. The soil samples were analyzed for $\mathrm{pH}$, organic Carbon $(\%)$, available nitrogen $(\mathrm{kg} / \mathrm{ha})$, available phosphorous (kg/ha) and available potassium ( $\mathrm{kg} / \mathrm{ha})$. The spatial distribution of nutrients showed that high available nitrogen content was observed at various parts of the Kuttanad agroecosystem except Vaikom Kari, northern part of North Kuttanad and western part of Kayal Lands. A cluster of area including southeast region of Lower Kuttanad, northern part of Purakkad Kari and north east regions of Upper Kuttanad as well as north east part of Vaikom Kari has showed the highest concentration of phosphorous. High intensity of potassium was observed in the central portion of Kayal Lands, North Kuttanad, northeast and southeast regions of Purakkad Kari and Lower Kuttanad respectively. It can conclude that monsoon flooding has a major role in the regulation of nutrients in the Kuttanad paddy fields. $\mathrm{N}$ and $\mathrm{P}$ are taken away from the soil by the inundated water whereas potassium is deposited in these areas. The high concentration of nutrients observed at the sites which are having more than one time cultivation and also watering and dewatering has a significant role in regulating the nutrient status of the Kuttanad agricultural wetland ecosystem.
\end{abstract}

Key words: Agroecosystem, Kuttanad, monsoon flooding, nutrient distribution, one time cultivation

\section{Introduction}

Acquiring detailed knowledge about the soil fertility status is a prerequisite for assessing the long-term impact of modern, intensive rice production technologies on paddy soils. Due to negative nutrient balances, significant depletion of soil nutrients such as potassium or phosphorous seems to occur in irrigated rice areas of tropical Asia [1,2,3]. Soil fertility deals with nutrient status and ability of soil to supply nutrients for optimum plant growth. However, the optimum nutrient status alone will not ensure soil productivity [4].

Soil characteristics are highly variable due to the combined effects of physical, chemical and biological processes that operate with different intensities and [5]. The spatial variability of soil properties is influenced by both intrinsic (soil formation factors, such as soil parent materials) and extrinsic agricultural management practices, such as fertilization and irrigation) factors [6]. Uniform management of fields often results in over-application of inputs in areas with high nutrient levels and underapplication in areas with low nutrient levels [7]. Besides natural landscape conditions, proper management and practices for highly productive paddy soils are characterized by high inputs of agricultural chemicals, e.g., chemical fertilizers. However, the amount of soil nutrients that moves through the environment, closely correlate with the soil nutrient contents and the applied fertilizers [8, 9].

The Kuttanad rice agroecosystem extends from $9^{\circ} 17^{\prime}-9^{\circ} 40^{\prime} \mathrm{N}$ and $76^{\circ} 19^{\prime}-76^{\circ} 33^{\prime} \mathrm{E}$ and is a unique system situated $0.6-2.2 \mathrm{~m}$ below mean sea level (msl). It is the delta of four major river systems in Kerala. It measures approximately $25 \mathrm{~km}$ east to west and $60 \mathrm{~km}$ north to south on the west coast of Kerala, in which about 53,639 hectares are used for rice cultivation. Much of this region remains water-logged almost throughout the year and is subjected to continued flood submergence during the monsoon and saline water ingression during the summer months [10] even though the Thanneermukkom 
barriage restrict the flow of saline water into the Kuttanad. The restriction of saline water caused for the decrease in flush out which was earlier regulated the nutrient dynamics. Most of these fields are inundated during the non-crop season and water has to be pumped out to the canal systems and backwaters before the commencement of the cultivating season [11].

The current knowledge about nutrient balances and soil fertility status in entire Kuttanad rice agroecosystems is less. Kuttanad agroecosystem, once the rice bowl of Kerala, is facing a serious threat from human activities. The indiscriminate use of chemical fertilizers in paddy fields and the Thannermukkom barriage influenced the nutrient dynamics of Kuttanad. A very few studies have been reported on the status of such a unique agroecosystem. Hence the present study assessed the nutrient status of Kuttanad paddy soils and the spatial distribution of Nutrients using GIS technique.

\section{$2 \quad$ Materials and Methods}

\subsection{Sampling}

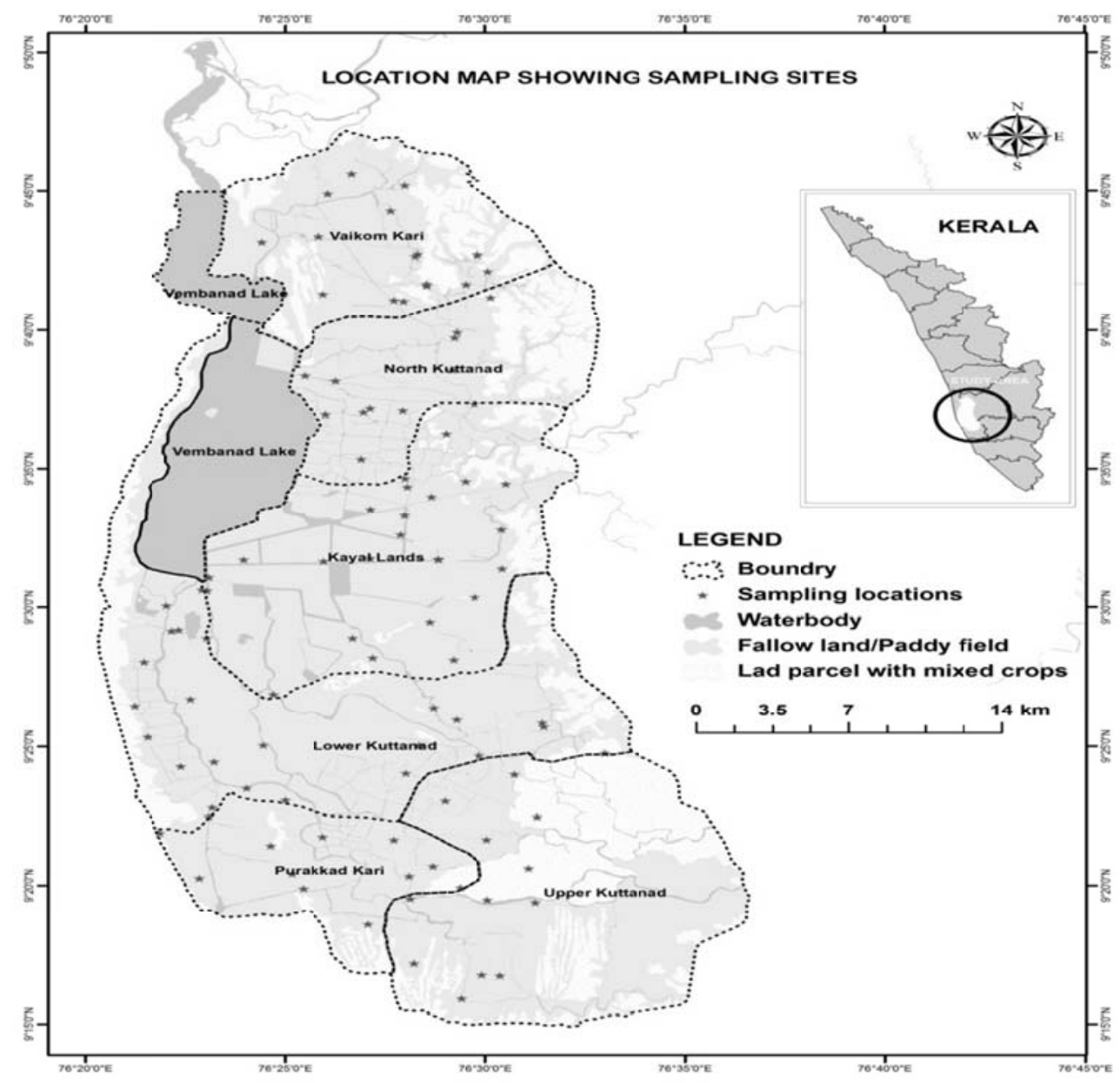

Figure 1. Study area map

For the collection of soil samples, Stratified random sample technique was used. Sampling sites were selected so as to represent the total amount of whole study area (Figure1). The soil samples were collected from 117points at $10-15 \mathrm{~cm}$ depth from each site. The grid size is $5 \mathrm{~km} \times 5 \mathrm{~km}$. The exact 
sample location was recorded using a Global Positioning System (GPS).

\subsection{Sample Preparation}

In the lab, soil samples were air dried and then ground to fine powder using an agate mortar. Then the samples were separated to granulometric fraction, $<200 \mu$ using ASTM sieves and this fraction was used for the chemical analysis. The correlations between parameters were statistically analyzed by the software SPSS.

\subsection{Chemical Analysis}

The $\mathrm{pH}$ was measured by digital $\mathrm{pH}$ meter. Soil nutrients such as Organic carbon, Nitrogen, Phosphorus and Potassium were analyzed by following methods:

- Organic Carbon-Walkley and Black Rapid titration method [12]

- Nitrogen- Alkaline Potassium permanganate method [13]

- Phosphorous-Bray's Method [14]

- Potassium-Morgan's extraction method [14]

The soil fertility maps were prepared using Arc GIS 9.3 software.

\section{$3 \quad$ Results}

The $\mathrm{pH}$ of the Kuttanad paddy soil was slightly acidic and ranged from 2.47-5.16 with a mean of 3.97 (Table 1). The Canal sediments of Kuttanad were also acidic $(3.73 \pm 0.69$. Maximum soil organic carbon recorded for the paddy fields is $16.6 \%$ where as in Canal it was $13.03 \%$ and the mean value recorded was $4.72 \%$ and $6.20 \%$ respectively. The Available N content of the Kuttanad soils ranged from $378 \mathrm{~kg} / \mathrm{ha}$ to $1386 \mathrm{~kg} / \mathrm{ha}$ with a mean of $771.91 \mathrm{~kg} / \mathrm{ha}$ and Av.N content in the canal sediment ranged from 378 to $1386 \mathrm{~kg} / \mathrm{ha}$ with a mean of $781.2 \mathrm{~kg} / \mathrm{ha}$ (Table 2). The maximum concentration of Av.P in the paddy fields of Kuttanad was $5.42 \mathrm{~kg} / \mathrm{ha}$ whereas the minimum concentration observed was 0.018 $\mathrm{kg} / \mathrm{ha}$. The canal sediments showed a range of 0.018 to $3.942 \mathrm{~kg} /$ ha with a mean of $0.71 \mathrm{~kg} / \mathrm{ha}$ for Av.P. The Av.K content varied from $29.12 \mathrm{~kg} /$ hato $884.8 \mathrm{~kg} / \mathrm{ha}$.

Table 1. Physico-chemical and nutrient concentration of soil samples collected from the paddy fields of entire kuttanad

\begin{tabular}{c|c|c|c|c|c|c|c}
\hline & $\mathbf{p H}$ & $\begin{array}{c}\text { OC } \\
(\mathbf{\%})\end{array}$ & $\begin{array}{c}\text { OM } \\
(\mathbf{\%})\end{array}$ & $\begin{array}{c}\text { Av.N } \\
(\mathbf{K g} / \mathbf{h a})\end{array}$ & $\begin{array}{c}\text { Av.P } \\
(\mathbf{K g} / \mathbf{h a})\end{array}$ & $\begin{array}{c}\text { Av.K } \\
(\mathbf{K g} / \mathbf{h a})\end{array}$ & $\begin{array}{c}\text { BD } \\
(\mathbf{g m} / \mathbf{c m} \mathbf{)})\end{array}$ \\
\hline Minimum & 2.47 & 0.9 & 1.552 & 1.552 & 378.00 & 0.018 & 29.12 \\
\hline Maximum & 5.16 & 16.6 & 28.618 & 28.618 & 5.420 & 5.420 & 884.80 \\
\hline MEAN & 3.97 & 4.72 & 8.140 & 771.910 & 0.71 & 322.320 & 0.60 \\
\hline SD & 0.56 & 2.59 & 4.460 & 218.720 & 1.27 & 142.940 & 0.21 \\
\hline
\end{tabular}

Table 2. Physico-chemical and nutrient concentration of soil samples collected from the canals of entire kuttanad

\begin{tabular}{c|c|c|c|c|c|c}
\hline & $\mathrm{pH}$ & $\begin{array}{c}\mathrm{OC} \\
(\%)\end{array}$ & $\begin{array}{c}\mathrm{OM} \\
(\%)\end{array}$ & $\begin{array}{c}\text { Av.N } \\
(\mathrm{Kg} / \mathrm{ha})\end{array}$ & $\begin{array}{c}\text { Av.P } \\
(\mathrm{Kg} / \mathrm{ha})\end{array}$ & $\begin{array}{c}\text { Av.K } \\
(\mathrm{Kg} / \mathrm{ha})\end{array}$ \\
\hline Minimum & 1.64 & 1.94 & 3.345 & 378 & 0.018 & 23.52 \\
\hline Maximum & 4.74 & 13.03 & 22.464 & 1386 & 3.942 & 1288 \\
\hline MEAN & 3.73 & 6.20 & 10.690 & 781.2 & 0.710 & 326.41 \\
\hline SD & 0.69 & 2.87 & 4.950 & 302.14 & 1.240 & 276.91 \\
\hline
\end{tabular}

The mean Av.N concentration (771.91 kg/ha) of paddy fields comes under high fertile classification (Table 3). Among the total 92 sites, 15 sites are coming under the medium fertility class $(272-544 \mathrm{~kg} / \mathrm{ha})$ and the others fall within high fertile class (77sites) depending on the nitrogen availability. The $84 \%$ of 
total soil sample was highly fertile in terms of nitrogen and other $16 \%$ came under medium fertile class. Exceptionally high Nitrogen content in some sites is due to the indiscriminate use of fertilizers by the farmers.

Table 3. Standard soil fertility classification based on nutrient content

\begin{tabular}{c|c|c|c}
\hline Status & Av.N (kg/ha) & Av.P (kg/ha) & Av.K (kg/ha) \\
\hline Low & $<272$ & $<9.8$ & $<120$ \\
\hline Medium & $272-544$ & $9.8-24.5$ & $120-280$ \\
\hline High & $>544$ & $>24.5$ & $>280$ \\
\hline
\end{tabular}

The Av.P content of entire Kuttanad was coming under low fertility class. The mean value of Av.P $(0.708 \mathrm{~kg} / \mathrm{ha})$ indicated that the entire Kuttanad paddy fields are low fertile in terms of phosphorus content (Fig 7).Similar results in acidic soils were also observed by [15, 16, 17]. Available phosphorus increases with $\mathrm{pH}$ and decreases with organic carbon and there will be conversion of water soluble inorganic phosphorus into unavailable form during the decomposition of organic residues of wide $\mathrm{C}$ : $\mathrm{P}$ ratio $[18]$.

Considering the potassium content, 3 sites were coming under the low fertility class $(<120)$, others are distributed between medium (14 sites) and high $(75$ sites) fertility classes. Hence the mean value $(326.41 \mathrm{~kg} / \mathrm{ha})$ showed that the entire Kuttanad paddy fields are highly fertile in terms of Av. K. Potassium was distributed in all the three classes of fertility and the lowest percentage of occurrence noticed for low fertility (4\%). $43 \%$ of the sample represented medium class while considering the potassium content, whereas $53 \%$ was under highly fertile class and only $4 \%$ is under low fertility (Figure 4). Earlier studies observed that low $\mathrm{pH}$ content is related to low potassium conte.

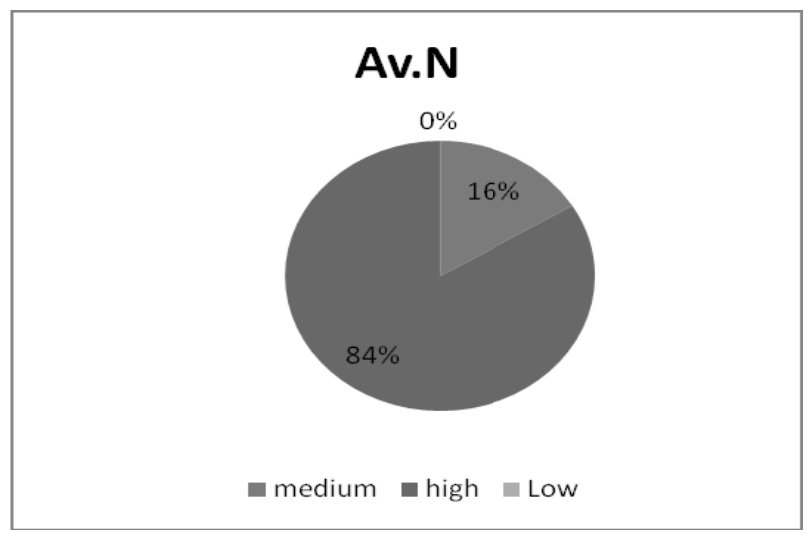

Figure 2. Classification of soil samples based on standard $\mathrm{N}$ fertility class

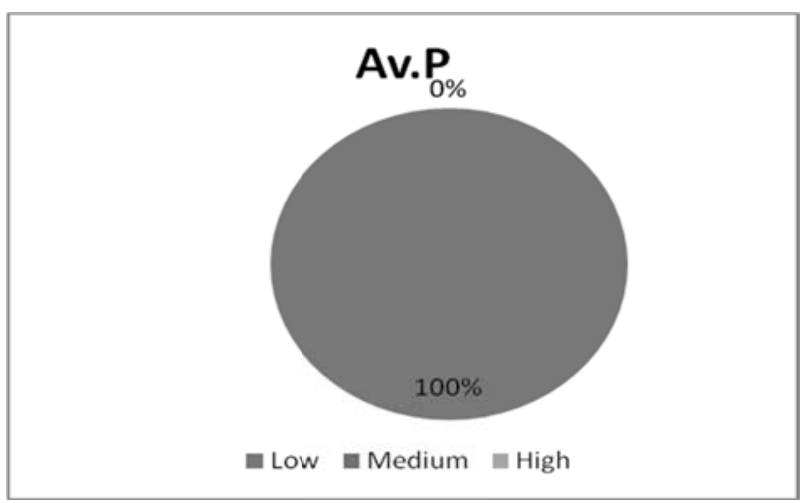

Figure 3. Classification of soil samples based on standard P fertility class 


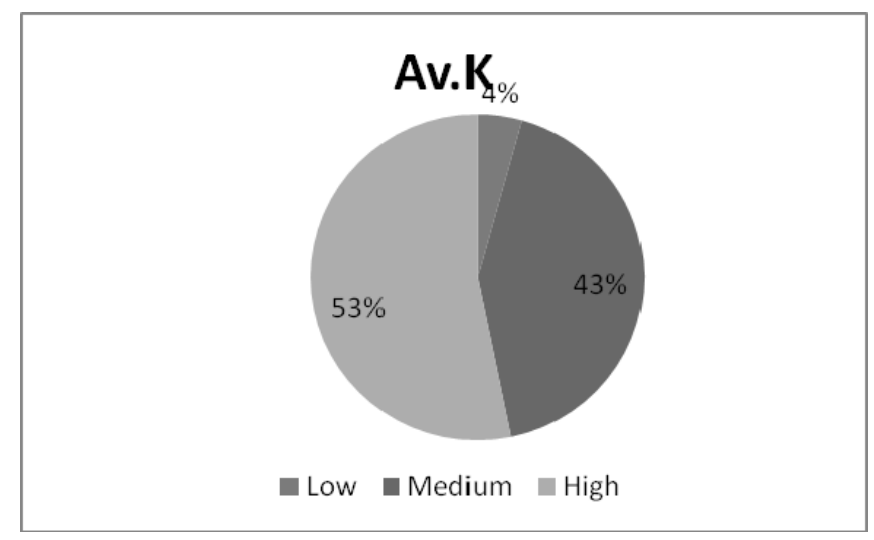

Figure 4. Classification of soil samples based on standard K fertility class

The results showed that the soils of Kuttanad paddy field are highly acidic. This might be due to the partial decomposition of organic matter accumulated in the system locally known as 'kari' (acid sulphate enriched with iron) nature of the soil [21, 22]. The occurrence of acid sulphate soil in the west coast of Kerala, comprises kari and kayal soil depending on their location [23]. The major factors governing the $\mathrm{pH}$ of the soil include the concentration of reduced iron, manganese, hydroxides, carbonates, carbonic acids, and humic acids [24]. The present study also showed the negative correlation of $\mathrm{pH}$ with organic carbon.

The soil organic carbon and organic matter content recorded for Kuttanad paddy fields is also high.

The return of rice straw into soil was considered to be the main reason for the increase in soil OC [8]. 50\% of the straw biomass is buried in the sediments, which later decomposes to release the nutrients like nitrogen, phosphorous and potassium to the sediments [25]. OC improves cation exchange and supplies nutrients such as nitrogen and phosphorous [26]. The available nitrogen content of the Kuttanad soils was high (mean $771.91 \mathrm{~kg} / \mathrm{ha}$ ). OC and $\mathrm{N}$ are positively correlated in this study but not significant.

The concentration of available $\mathrm{P}$ in Kuttanad is very low. Phosphates in wetlands are easily taken up by the aquatic plants [27]. The higher the soil acidity, the larger the immobilization of $\mathrm{P}$ added in soils. Change in available nutrient contents was related with fertilizer applications, which were also influenced by soil properties [28]. The growth of aquatic plants for a long time during the flooding might be major reason for the lower $\mathrm{P}$ content in the Kuttanad soil.

The Av.K content of the soil of Kuttanad agroecosystem is also high. Studies have showed that application of rice straw significantly increased available $\mathrm{K}$ by increasing organic matter contents. Soil organic matter played a major role in holding and supply of $\mathrm{K}$.

\subsection{Spatial Dispersion of Nutrients in Kuttanad}

The spatial distribution map of available N (Figure 5) shows that high available nitrogen content was observed at various parts of the kuttanad agroecosystem except Vaikom kari, Northern part of North Kuttanad and Western part of Kayal Lands. This might have owed to the monsoon flooding of the region. The regions with low content of available nitrogen having monsoon flooding, might have caused the dissolution of available $\mathrm{N}$ from the soil to water column. A cluster of areas including Southeast region of Lower Kuttanad, northern part of Purakkad Kari and North east regions of Upper Kuttanad as well as North east part of Vaikom kari have showed the highest concentration of phosphorous (Figure 7). Here also we can suspect the role of monsoon flooding in this mode of distribution. Available Potassium (Figure 6) showed an entirely different pattern. The central portion of Kayal lands, North Kuttanad, Northeast and southeast corner of Purakkad Kari and Lower Kuttanad have high intensity of potassium occurred. The high intensity regions of potassium were present where the intensity of $\mathrm{Av} P$ and Av N were low. 


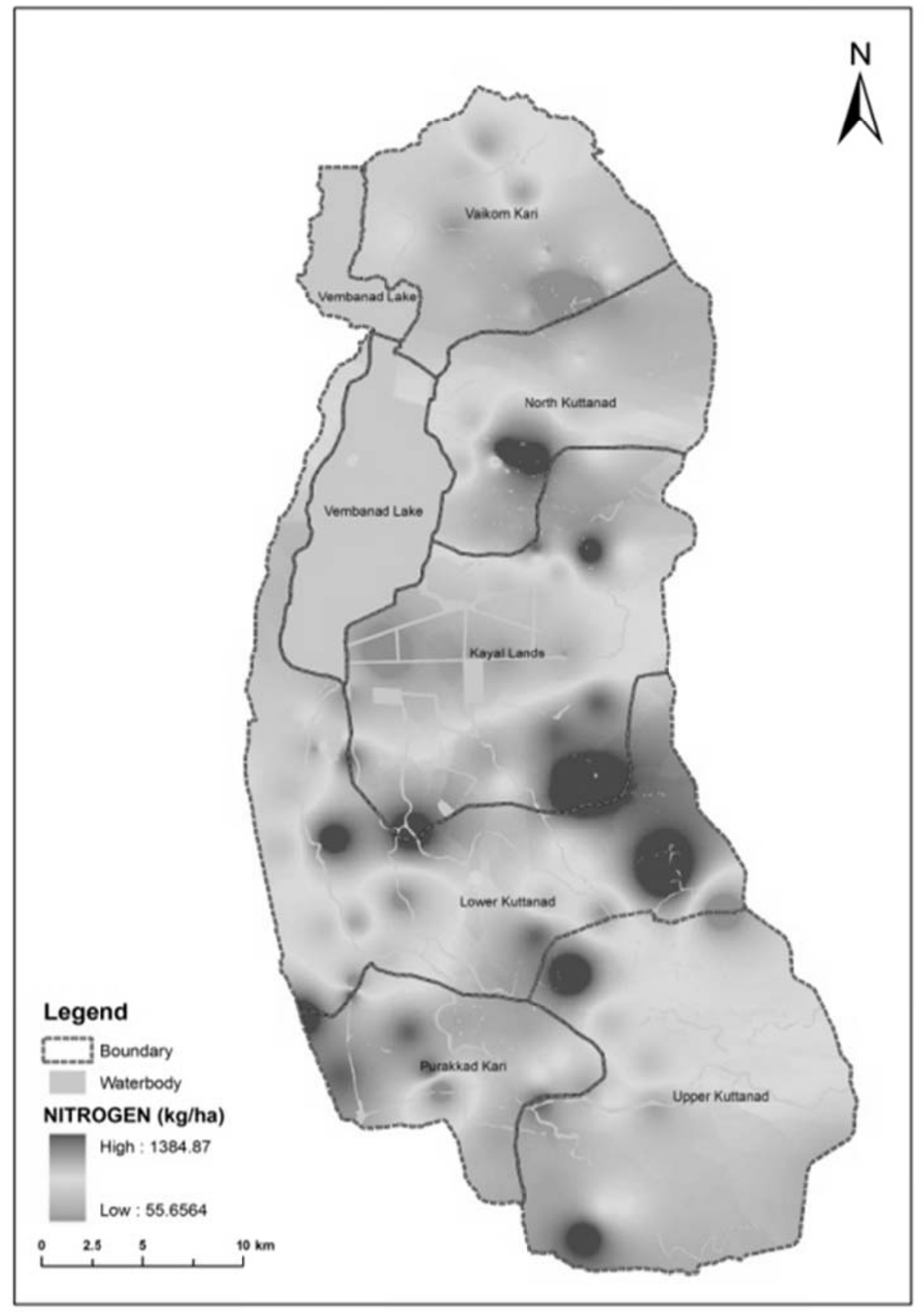

Figure 5. Spatial distribution map of available N 


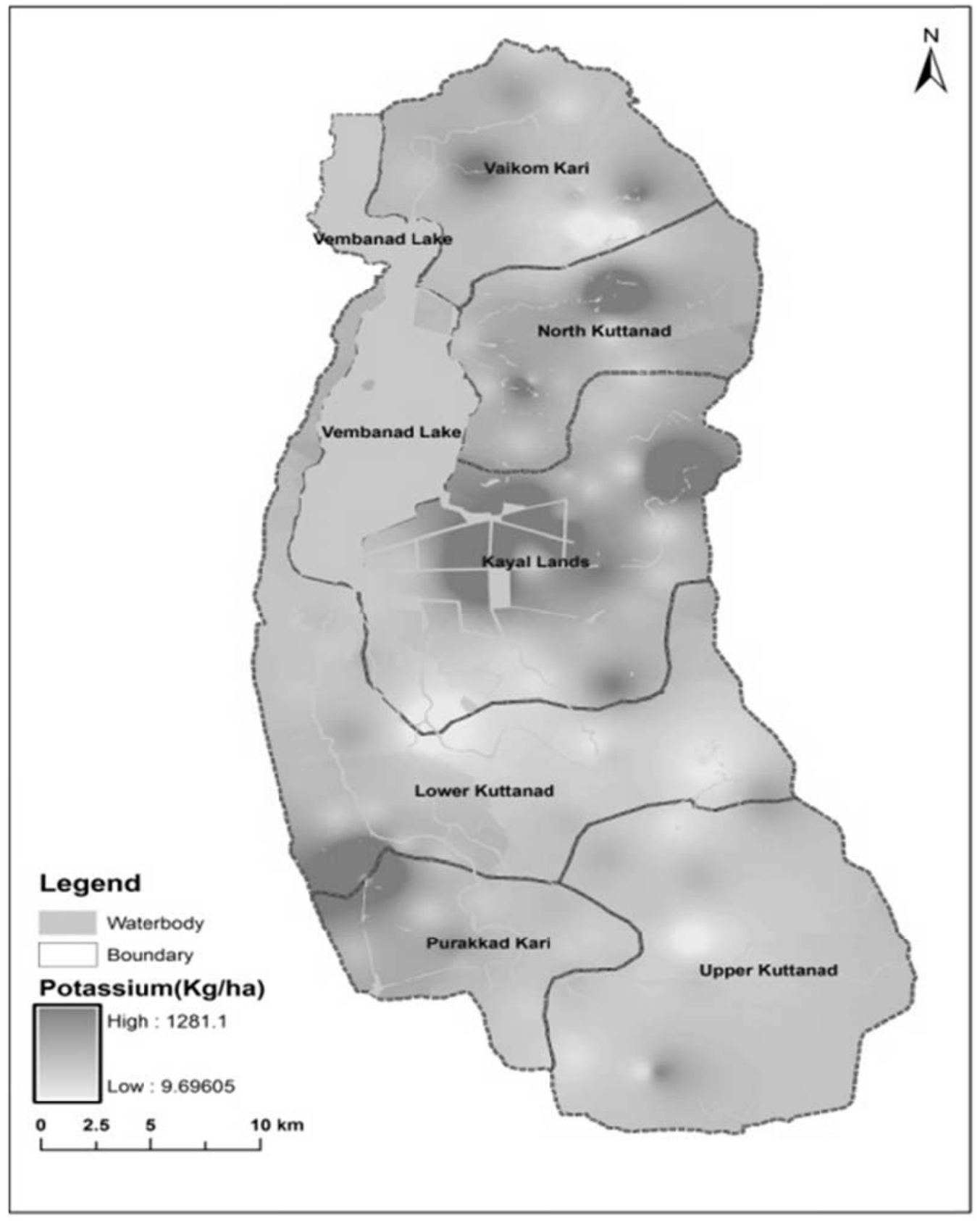

Figure 6. Spatial distribution map of available Potassium 


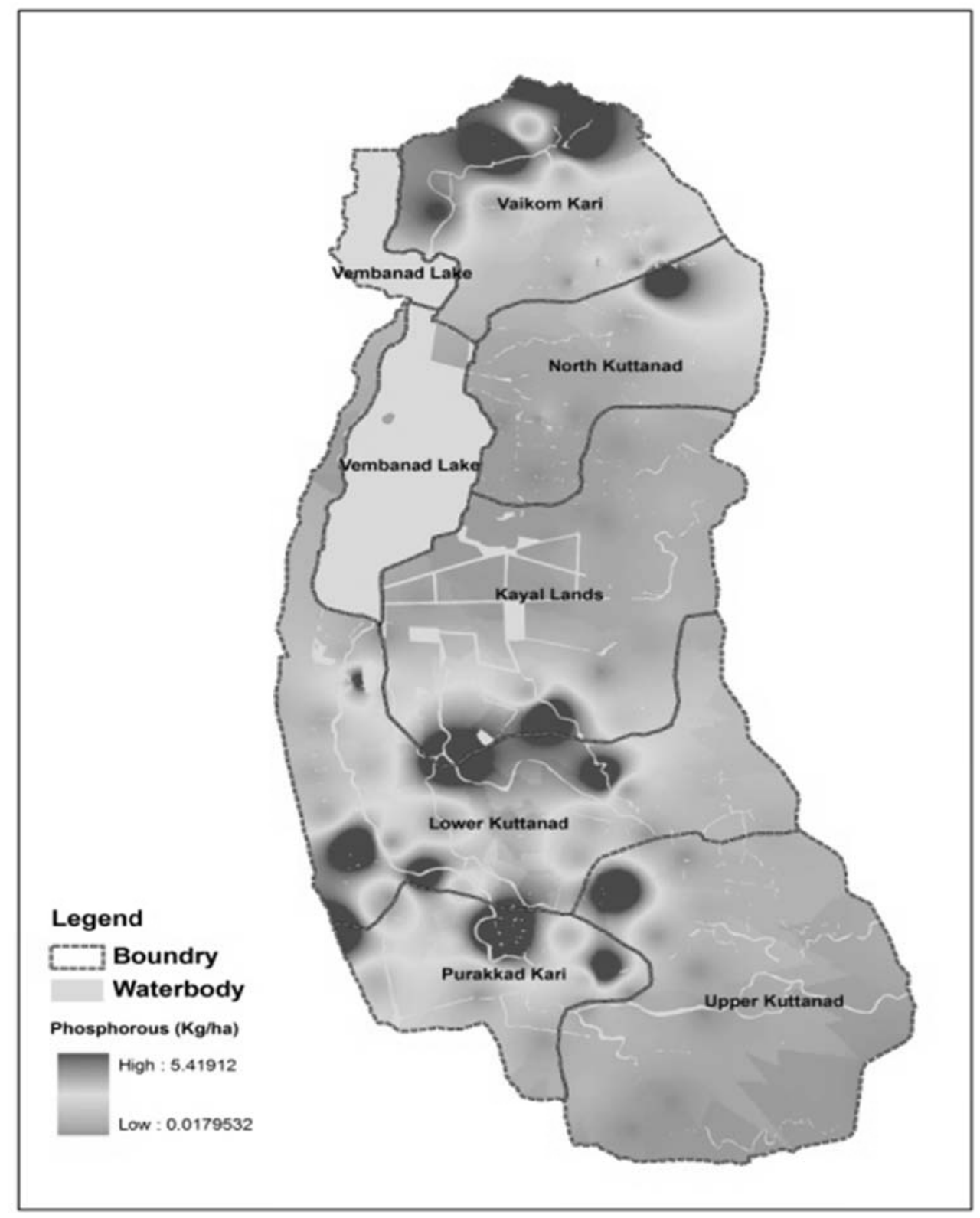

Figure 7. Spatial distribution map of available Phosphorous

The monsoon flooding will have a significant role in regulation of nutrients in the Kuttanad paddy fields as it is florished by fresh water from major four rivers of Kerala. Also the reduced flushout during summer seasosn due to Thanneermukkom barriage may influence the nutrient dynamics of the system. $\mathrm{N}$ and $\mathrm{P}$ are taken away from the soil by the inundated water whereas potassium is deposited in these areas. 


\section{Conclusion}

The soils of Kuttanad paddy fields are highly acidic, rich in organic matter and organic carbon. The soils are highly fertile in terms of available nitrogen and potassium contents and low fertile in terms of available phosphorous content. The spatial distribution of nutrients showed that $\mathrm{N}$ and $\mathrm{P}$ are low at sites where the condition is longtime flooding. The high concentration of nutrients was observed at the sites which are having more than one time cultivation. The results showed that the watering and dewatering has a significant role in regulating the nutrient status of the Kuttanad agricultural wetland ecosystem.

\section{References}

1. Tiwari, K. N., Nigam, V., Pathak, A. N., 1985. Studies on the potassium requirements of different crops. Nutrient Cycling in Agroecosystems, 8(1), 91-96.

2. De Datta, S. K., Gomez, K. A., Descalsota, J. P., 1988. Changes in yield response to major nutrients and in soil fertility under intensive rice cropping. Soil Science, 146(5), 350-358.

3. Dobermann, A., Cruz, P. S., Cassman, K. G., 1996. Fertilizer inputs, nutrient balance, and soil nutrientsupplying power in intensive, irrigated rice systems. I. Potassium uptake and $\mathrm{K}$ balance. Nutrient Cycling in Agroecosystems, 46(1), 1-10.

4. Sumner, M. E. (Ed.)., 1999. Handbook of soil science. CRC press.

5. Goovaerts, P., 1998. Geostatistical tools for characterizing the spatial variability of microbiological and physicochemical soil properties. Biology and Fertility of soils, 27(4), 315-334.

6. Babu, K. N., Omana, P. K., Mohan, M., 2010. Water and sediment quality of Ashtamudi estuary, a Ramsar site, southwest coast of India - a statistical appraisal. Environmental monitoring and assessment, 165(1), 307-319.

7. Ferguson, R. B., Hergert, G. W., Schepers, J. S., Gotway, C. A., Cahoon, J. E., Peterson, T. A., 2002. Sitespecific nitrogen management of irrigated maize. Soil Science Society of America Journal, 66(2), 544-553.

8. Cao, Z. H., 2003. Effect of fertilization on water quality - Effect of fertilization on environment quality (2). Soils, 35(5), 353-363.

9. Lu, R. K., 2003. The phosphorus level of soil and environmental protection of water body. Phosphate and Compound Fertilizer, 18(1), 4-8.

10.Sudhikumar, A. V., Mathew, M. J., Sunish, E., Sebastian, P. A., 2005. Seasonal variation in spider abundance in Kuttanad rice agroecosystem, Kerala, India (Araneae). European Arachnology, 1, 181-190.

11.Sashikumar, C., Palot, M. J., 1996. Wetlands and waterfowls of Kerala, India-an Overview. In Birds of Wetlands and Grasslands. Proceedings of the Salim Ali Centenary Seminar on Conservation of Avifauna of Wetlands and Grasslands (pp. 147-153).

12.Jackson, M. L., 1958. Soil chemical analysis. Prentice Hall of India Private Limited, New Delhi.1973.

13.Subbiah, B. V., Asija, G. L., 1956. A rapid procedure for the estimation of available nitrogen in soils. Current science, 25(8), 259-260.

14.Baruah, T. C., Barthakur, H. P., 1997. A text book of soil analysis. Vikas publishing house pvt. Ltd., New Delhi.

15.Badrinath, A. M., Krishnappa, A. M., Kenchain, K., Balakrishna Rao, K., 1986. Fertility status of some typical soils of coastal Karnataka. J. Indian Soc. Soil Sci, 34, 436-438.

16.Viswanath, D. P., Perur, N. G., Rao, B. V. V., 1978. "Zinc and major nutrient status of some soils of heavy rainfall coastal mountainous region of Karnataka" Current Research, Vol. 7, pp. 152-154.

17.Ramamoorthy, B., Bajaj, J. C., 1969. Available nitrogen, phosphorus and potassium status of Indian soils. Fertiliser news.

18.Tomar, N. K., Chand, T., 1992. Effect of soil properties on the transformation of phosphorus in acid soils. Journal of the Indian Society of Soil Science, 40(2), 257-261.

19.Ranganathan, A., Satyanarayana, T., 1980. Studies on potassium status of soils of Karnataka. Journal of the Indian Society of Soil Science, 28(2), 148-153.

20.Ano, A. A., 1991. Potassium status of the Nigerian coastal plain sands. Journal of potassium Research, 7(4), 247254. 
21.Kurup, B., 1994. Nutrient status of kari lands of Kuttanad, In: A glimpse to problem soils of Kerala, Kerala Agricultural University, Thrissur, 16-32.

22.Mathews, D. V., 2005. "Response of rice to soil fertility constraints and bio-fertilizers in coastal alluvial soil of Karnataka," Thesis submitted to the University of Agricultural Sciences, Dharwad.

23.Patnaik, S., Mandal, L. N., 1982. Chemistry of submerged rice soils. In Review of Soil Research in India. I2th International Congress of Soil Science, New Delhi (pp. 181-189).

24.Patrick, W. H., Mikkelsen, D. S., Wells, B. R., 1985. Plant nutrient behavior in flooded soil. Fertilizer technology and use, (fertilizertechn), 197-228.

25.Fores, E., Comín, F. A., 1992. Ricefields, a limnological perspective. Limnetica, 8, 101-109.

26.Rieley, J. O., Page, S. E., 1990. Ecology of plant communities. A phytosociological account of the British vegetation. Longman Scientific and Technical.

27.Richardson, C. J., 1985. Mechanisms controlling phosphorus retention capacity in freshwater wetlands. Science (Washington), 228(4706), 1424-1426.

28.Huang, W., Campredon, R., Abrao, J. J., Bernat, M., Latouche, C., 1994. Variation of heavy metals in recent sediments from Piratininga Lagoon (Brazil): interpretation of geochemical data with the aid of multivariate analysis. Environmental Geology, 23(4), 241-247. 